\title{
HIV-1 Drug Resistance Among Ugandan Adults Attending an Urban Out-Patient Clinic
}

\author{
Amrei von Braun, MD, * Christine Sekaggya-Wiltshire, MD, * Nadine Bachmann, $+\neq$ \\ Deogratius Ssemwanga, PhD, $\S$ Alexandra U. Scherrer, PhD, $+\neq$ Maria Nanyonjo, $\S$ Anne Kapaata, $\S$ \\ Pontiano Kaleebu, $\S$ Huldrych F. Günthard, $\dagger \neq$ Barbara Castelnuovo, MD, PhD, * Jan Fehr, $\dagger \|$ and \\ Andrew Kambugu, MD*
}

Background: Little is known about prevalence of drug resistance among HIV-infected Ugandans, a setting with over 15 years of public sector access to antiretroviral therapy (ART) and where virological monitoring was only recently introduced.

Setting: This study was conducted in the adults' out-patient clinic of the Infectious Diseases Institute, Kampala, Uganda.

Methods: HIV genotyping was performed in ART-naive patients and in treatment-experienced patients on ART for $\geq 6$ months with virological failure $(\geq 1000$ copies $/ \mathrm{mL})$.

Results: A total of 152 ART-naive and 2430 ART-experienced patients were included. Transmitted drug resistance was detected in 9 $(5.9 \%)$ patients. After a median time on ART of 4.7 years [interquartile range: $2.5-8.7$ ], 190 patients (7.8\%) had virological failure with a median viral load of $4.4 \log 10$ copies per milliliter (interquartile range: $3.9-4.9$ ). In addition, 146 patients had a viral load between 51 and 999 copies per milliliter. Most patients with virological failure $(142,74.7 \%)$ were on first-line ART. For 163 (85.8\%) ART-experienced patients, genotype results were available. Relevant drug-resistance mutations were observed in $135(82.8 \%)$, of which 103 (63.2\%) had resistance to 2 drug classes, and $11(6.7 \%)$ had resistance to all drug classes available in Uganda.

Received for publication January 3, 2018; accepted April 23, 2018.

From the *Research Department, Infectious Diseases Institute, College of Health Sciences, Makerere University, Kampala, Uganda; $†$ Division of Infectious Diseases and Hospital Epidemiology, University Hospital Zurich, University of Zurich, Zurich, Switzerland; $\ddagger$ Institute of Medical Virology, University of Zurich, Zurich, Switzerland; §Uganda Research Unit, Medical Research Council/Uganda Virus Research Institute (MRC/ UVRI), London School of Hygiene and Tropical Medicine, Entebbe, Uganda; and \|Department of Public Health at Epidemiology, Biostatistics and Prevention Institute, University of Zurich, Zurich, Switzerland.

Supported by Swiss HIV Cohort Study, Gilead Sciences.

Presented in part at the following conference: HIV Drug Therapy Glasgow; October 24-26, 2016; Glasgow, Scotland.

The authors have no conflicts of interest to disclose.

A.v.B., S.S.-W., J.F., and A.N. contributed to the manuscript equally.

Correspondence to: Amrei von Braun, Division of Infectious Diseases, Tropical Medicine, Leipzig University Hospital, Liebigstrasse 20, 04103 Leipzig, Germany (e-mail: amrei.braun@medizin.uni-leipzig.de).

Copyright (C) 2018 The Author(s). Published by Wolters Kluwer Health, Inc. This is an open-access article distributed under the terms of the Creative Commons Attribution-Non Commercial License 4.0 (CCBY-NC), where it is permissible to download, share, remix, transform, and buildup the work provided it is properly cited. The work cannot be used commercially without permission from the journal.

Conclusion: The prevalence of transmitted drug resistance was lower than recently reported by the WHO. With $92 \%$ of all patients virologically suppressed on ART, the prevalence of virological failure was low when a cutoff of 1000 copies per milliliter is applied, and is in line with the third of the 90-90-90 UNAIDS targets. However, most failing patients had developed multiclass drug resistance.

Key Words: HIV drug resistance, virological failure, Uganda, treatment monitoring

(J Acquir Immune Defic Syndr 2018;78:566-573)

\section{INTRODUCTION}

In Uganda, antiretroviral therapy (ART) was first made available for selected HIV-infected patients through the private sector and small pilot research studies in 1998, approximately 5 years earlier than in other countries in subSaharan Africa. ${ }^{1}$ When low-cost, high-quality generic antiretroviral drugs became available in 2001, the Ugandan government introduced ART for HIV-infected patients with advanced HIV disease funded by the World Bank MultiSectoral AIDS Project (MAP). ${ }^{2,3}$ Since 2003, ART in Uganda is largely funded by the US President's Emergency Plan for HIV/AIDS Relief (PEPFAR) and has been made available to a large part of HIV-infected Ugandans based on existing national guidelines. ${ }^{4}$ According to the Ugandan Population HIV Impact Assessment (UPHIA), 1.3 million people in Uganda were living with HIV in 2016 (prevalence 6.2\% among adults), and the ART coverage was $60 \%{ }^{5}$

In line with $\mathrm{WHO}$ guidelines, first-line treatment regimens in Uganda consist of a fixed-dose combination of 2 nucleoside reverse transcriptase inhibitors (NRTIs), either AZT/3TC or TDF/3TC, with 1 nonnucleoside reverse transcriptase inhibitor (NNRTI), either nevirapine or efavirenz. ${ }^{4}$ Second-line treatment options are reserved for patients failing first-line treatment and consist of a protease inhibitor (PI) with 2 NRTIs. Integrase inhibitors such as raltegravir or dolutegravir are considered thirdline drugs and were only available through research studies or private purchase at the time of study implementation.

Previous studies on the prevalence of transmitted drug resistance in Uganda mainly focused on key populations or had small patient numbers. For instance, a study from 2004 included 81 patients from Kampala and found a prevalence of transmitted drug resistance of $7 \%{ }^{6}$ A more recent, but 
similarly small study examined transmitted drug resistance among Ugandan fishing communities, which is a high-risk group around Lake Victoria, and found resistance to NNRTI in 3 of $47(6.4 \%)$ treatment-naive patients. $^{7}$

As resistance mutations impact therapeutic outcomes, in developed countries, genotypic resistance testing is recommended before starting treatment and before considering a switch of regimen. ${ }^{8}$ However, genotypic resistance testing remains costly and is therefore reserved for research or privately paid for in resource-limited countries including Uganda. A meta-analysis has shown a higher prevalence of HIV drug resistance among ART-naive patients in East Africa compared with other regions with a $29 \%$ increase of HIV drug resistance per year since the ART roll out, compared with lower rates in Southern Africa (14\%) and Central and West Africa (3\%). ${ }^{9}$ Because of growing evidence of increasing resistance to ART, there is need for further documentation of the current state of both acquired and transmitted drug resistance in Uganda. ${ }^{10-12}$ The objective of our study was to report the type and frequency of HIV drug resistance among ART-naive, as well as ART-experienced urban Ugandan adults by performing a cross-sectional study in one of the largest HIV treatment centers in Kampala.

\section{METHODS}

\section{Setting}

We conducted a cross-sectional study at the adult clinic of the Infectious Diseases Institute (IDI), College of Health Sciences, Makerere University in Kampala, Uganda, between June 4 and September 30, 2015. The IDI is a center of excellence for HIV treatment located at the national referral hospital complex, and currently cares for over 8000 registered patients infected with HIV. ${ }^{13}$ Up to December 2014, patients on ART were monitored with CD4 count measurements every 6 months, whereas viral load testing was made available only for patients who were thought to have treatment failure based on immunological or clinical criteria. ${ }^{14}$

All HIV-infected patients presenting at the IDI during the study period, who were 18 years or older, ART-naive or on ART for $\geq 6$ months, and due for a CD4 cell count measurement were eligible for study participation. As defined by the WHO, ${ }^{15}$ transmitted HIV drug resistance is detected in ART-naive people with no history of antiretroviral drug exposure. Therefore, all patients currently without ART but previous exposure to ART, such as women with a history of treatment for the prevention-of-mother-to-child-transmission (PMTCT), were excluded. Patients with a history of any blinded ART regimen in the context of clinical trials were excluded as well. Patients were consecutively screened and enrolled by trained study staff.

\section{Study Procedures}

For each participant, we collected information on demographics, social and educational background, ART history, concomitant medication including herbal remedies, alcohol and recreational drug use, information on adherence by self-report, side effects, past CD4 cell counts, and, if applicable, past viral load results. Results for viral loads and genotypic resistance testing were collected prospectively. Venous blood was drawn from patients on ART for viral load measurement and plasma storage at $-80^{\circ} \mathrm{C}$. CD4 cell counts (BD FACSCalibur Flow Cytometer: 4-Color) and viral load measurements (COBAS AmpliPrep/COBAS TaqMan HIV-1 Test, v2.0, Roche Diagnostics, cutoff 20 copies per milliliter) were performed at the Makerere-University-John-Hopkins-University (MUJHU) CORE laboratory certified by the College of American Pathologists. For ART-naive patients, blood was sampled for plasma storage only. Genotyping was requested at the MRC/UVRI Uganda Research Unit on AIDS, HIV Drug Resistance Reference Laboratory for all ART-naive patients and ART-experienced patients with virological failure, defined as viral load $\geq 1000$ copies per milliliter. As previously described, viral RNA was extracted from $140 \mu \mathrm{l}$ of plasma using the QIAmp Viral RNA mini kit (Qiagen), the entire protease (codons 1-99) and amino terminus of reverse transcriptase (codons 1-320) were amplified and sequenced using the ABI 3500 machine (Applied Biosystems). ${ }^{12}$ Sequences were base-called using Sequencher v5.2.4, and drug resistance mutations (DRMs) were analyzed using the Stanford HIVdb Program (https:/hivdb.stanford.edu/hivdb/by-mutations). The assigned DRMs were interpreted using the 2009 WHO list for epidemiological surveys. HIV-1 subtyping was performed using SCUEAL (http://www.datamonkey.org/dataupload_scueal.php) and REGA (www.bioafrica.net/rega-genotype/html/ subtypinghiv.html) online software. Basic phylogenies were performed to determine sequence relatedness and to rule out contaminations. Viral sequences are available in Genbank accession numbers MF565526-MF565688.

\section{Data Management and Statistical Analysis}

Data were collected from patient interview, extracted from the electronic medical record (Integrated Clinic Enterprise Application, ICEA) ${ }^{16}$ or paper file and entered into DataFax forms specially designed for this study. The data management system DataFax is designated to manage paper data forms. The forms are faxed to the DataFax server where they are read using intelligent characters-recognition and populate the study database.

Univariate and multivariate logistic regressions were performed to identify risk factors for virological failure in patients on first- and second-line ART. The following potential risk factors or correlates for virological failure were considered in the univariate analysis: age, sex, current ART regimen, years on ART, CD4 cell count, number of children, marital status, adherence to ART, reported side effects, and previous viral load measurements. For the subsequent multivariate analysis, we selected all variables with a $P$ value $<0.1$ in the univariate model, checked for multicollinearity, and in case of multicollinearity selected according to clinical relevance.

\section{Ethical Considerations}

This study was reviewed and approved by the Makerere University School of Biomedical Research and Ethics 
Committee (SBS254), and the Uganda National Council for Science and Technology (HS 1800). The study was registered on ClinicalTrials.gov (NCT02507921). Written informed consent was obtained from all participants before enrollment. The funders had no role in study design, data collection, data analysis, data interpretation, or writing of the manuscript.

\section{RESULTS}

A total of 2808 participants were enrolled in the study consisting of 220 ART naive and 2588 ART experienced, respectively. Figure 1 depicts the disposition of patients from screening to enrollment.

\section{ART-Naive Patients}

After withdrawing 14 patients with a history of PMTCT, 206 ART-naive patients were included. The median age was 33 years (IQR: 26-41), and most patients had WHO disease stage $1(84,40.8 \%)$ or $2(76,36.9 \%)$. The median CD4 cell count was 511 cells/ $\mu$ L (IQR: $284-713$ ). A total of $91(44.2 \%)$ were either married or cohabitating, of which 59 $(64.8 \%)$ reported to have an HIV-infected partner. The majority of the partners $(54,91.5 \%)$ were already on ART. Fourteen patients $(6.8 \%)$ reported to have HIVinfected children.

Drug-resistance testing could be performed in 152 ART-naive patients. Mutations associated with HIV drug resistance were found in 9/152 (5.9\%) patients. Five patients (5/152, 3.3\%) had any NRTI mutation (K65R: 1, M184V: 2, and other: 2), and 8/152 (5.3\%) had any NNRTI mutation (K101E: 3, Y181C: 2, and K103N: 2, other: 4). No major PI mutation was detected.

\section{ART-Experienced Patients}

After withdrawing 158 patients, 2430 ART-experienced patients were included in this study, of which $1526(62.8 \%)$ were female. Patients were withdrawn for the following reasons: history of blinded ART regimen $(n=140)$, current ART regimen $<6$ months $(n=12)$, and unwillingness to give a blood sample $(n=6)$. Overall, study participants had been on ART for a median time of 4.7 years (IQR: 2.5-8.7 years). A total of $190(7.6 \%)$ participants had virological failure with a median viral load of $4.4 \log _{10}$ copies per milliliter (IQR: 3.9-4.9 $\log _{10}$ copies per milliliter). The majority of patients with virological failure were female $(131 / 190,69.0 \%)$ and on first-line ART $(142 / 190,74.7 \%)$. Table 1 shows baseline characteristics of study participants with virological suppression, as well as virological failure disaggregated by subjects failing first- and second-line ART regimens.

Risk factors for virological failure in patients failing first- and second-line ART were evaluated by univariate and multivariate analyses. As shown in Figure 2 for all patients, virological failure was significantly more likely in patients on second-line ART [adjusted odds ratio (aOR): 2.95, 95\% confidence interval (95\% CI): 1.87-4.65]. Furthermore, being separated from the spouse (aOR: $1.86,95 \% \mathrm{CI}: 1.12-3.01$ ) and reported side effects (aOR: 1.94, 95\% CI: 1.18-3.19) were associated with virological failure. Previous viral load measurements (aOR: 0.55, 95\% CI: 0.37-0.83), as well as excellent adherence (aOR: 0.41, 95\% CI: 0.24-0.71) were protective of virological failure. Results of the univariate and multivariate analysis were further disaggregated by patients failing on first- and second-line ART. For patients on first-line ART (Table 2A), reported side effects (aOR: 2.01, 95\% CI: $1.17-3.46$ ), as well as living separated from the spouse (aOR: 2.21, 95\% CI: 1.29-3.81) were strongly associated with virological failure. Excellent adherence was protective of virological failure (aOR: 0.33, 95\% CI: 0.18-0.61). In our study population, virological failure was significantly more likely to occur in patients on second-line treatment. In these patients (Table 2B), virological failure was associated with being single or separated from the spouse (aOR: 1.46, 95\% CI: 0.55-3.92). A low CD4 cell count was not associated with virological failure. However, this may be due to a small sample size of patients failing on second-line treatment $(\mathrm{N}=$ 48). Previous viral load measurements (aOR: $0.21,95 \% \mathrm{CI}$ : 0.09-0.52) were strongly protective of virological failure in patients on second-line ART.

Of 190 patients with a viral load $>1000$ copies per milliliter, HIV genotyping tests were available from 163

FIGURE 1. Enrollment process.

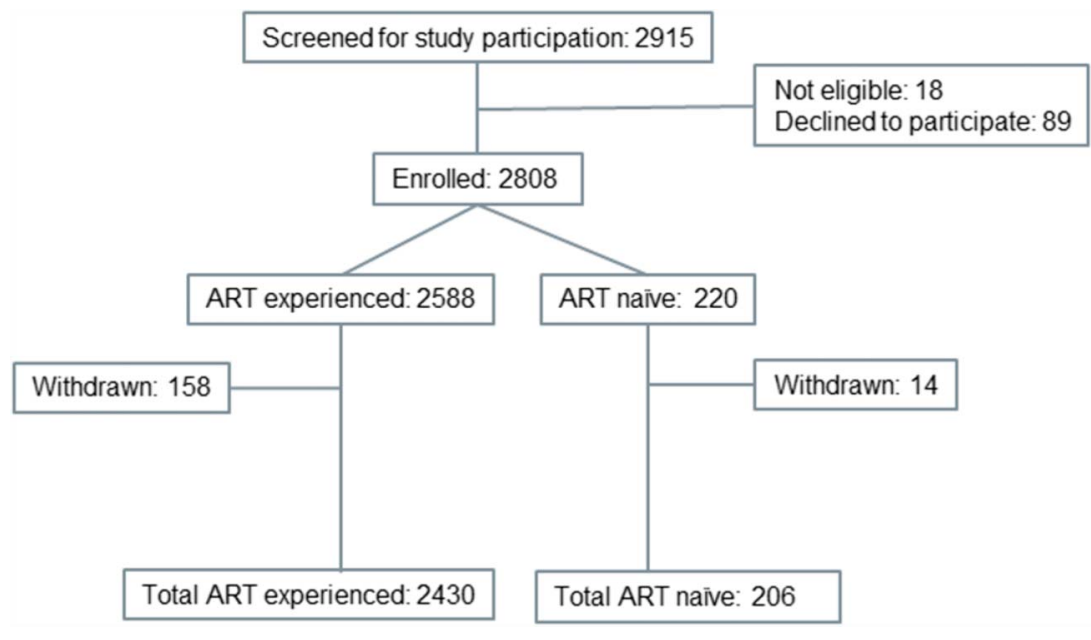


TABLE 1. Baseline Characteristics of Patients With and Without Virological Failure

\begin{tabular}{|c|c|c|c|}
\hline & Not Failing & Failing First Line & $\begin{array}{c}\text { Failing } \\
\text { Second Line }\end{array}$ \\
\hline Characteristics & $N=2240$ & $N=142$ & $N=48$ \\
\hline Female sex $(\mathrm{N}, \%)$ & $1395(62.3)$ & $102(71.8)$ & $29(60.4)$ \\
\hline $\begin{array}{l}\text { Median age in yr } \\
\text { (IQR) }\end{array}$ & $42(35-49)$ & $35(28-42)$ & $41(35.8-45.5)$ \\
\hline \multicolumn{4}{|l|}{$\begin{array}{l}\text { WHO disease stage } \\
(\mathrm{N}, \%)\end{array}$} \\
\hline 1,2 & $806(36.0)$ & $60(42.3)$ & $11(23.0)$ \\
\hline 3,4 & $1434(64.0)$ & $82(57.7)$ & $37(77.0)$ \\
\hline \multicolumn{4}{|l|}{$\begin{array}{l}\text { Median CD4 cell } \\
\text { count in cells } / \mu 1 \\
\text { (IQR) }\end{array}$} \\
\hline Current & $491(350-657)$ & $254(106.2-404.2)$ & $325(200-453)$ \\
\hline Nadir & $129(44-235)$ & $126.5(43-202.8)$ & $43.5(9-106.5)$ \\
\hline $\begin{array}{l}\text { Median time on ART } \\
\text { in yr (IQR) }\end{array}$ & $5.2(2.8-9.4)$ & $3.3(1.8-5.1)$ & $6.1(4.3-9.9)$ \\
\hline \multicolumn{4}{|l|}{$\begin{array}{l}\text { Current ART regimen } \\
(\mathrm{N}, \%)\end{array}$} \\
\hline $\begin{array}{l}\text { First-line NNRTI } \\
\text { based }\end{array}$ & $1932(86.3)$ & $142(100)$ & 0 \\
\hline $\mathrm{TDF}+\mathrm{XTC}+\mathrm{NVP}$ & 138 & $16(11.3)$ & 0 \\
\hline $\mathrm{TDF}+\mathrm{XTC}+\mathrm{EFV}$ & 712 & $54(38.0)$ & 0 \\
\hline $\mathrm{ZDV}+\mathrm{XTC}+\mathrm{NVP}$ & 624 & $47(33.1)$ & 0 \\
\hline $\mathrm{ZDV}+\mathrm{XTC}+\mathrm{EFV}$ & 436 & $24(16.9)$ & 0 \\
\hline $\mathrm{ZDV}+3 \mathrm{TC}+\mathrm{TDF}$ & 7 & $1(0.7)$ & 0 \\
\hline $\mathrm{D} 4 \mathrm{~T}+\mathrm{XTC}+\mathrm{NVP}$ & 3 & 0 & 0 \\
\hline $\mathrm{ABC}+\mathrm{XTC}+\mathrm{EFV}$ & 7 & 0 & 0 \\
\hline $\mathrm{ABC}+\mathrm{XTC}+\mathrm{NVP}$ & 5 & 0 & 0 \\
\hline $\begin{array}{l}\text { Second-line PI } \\
\text { based }\end{array}$ & $308(13.7)$ & 0 & $48(100)$ \\
\hline $\mathrm{ATV} / \mathrm{r}$ & 86 & 0 & $16(33.3)$ \\
\hline $\mathrm{LPV} / \mathrm{r}$ & 222 & 0 & $32(66.6)$ \\
\hline
\end{tabular}

$\mathrm{ATV} / \mathrm{r}$, ritonavir-boosted atazanavir; $\mathrm{EFV}$, efavirenz; LPV/r, ritonavir-boosted lopinavir; NVP, nevirapine; TDF, tenofovir; XTC, FTC or 3TC; ZDV, zidovudine.

(85.8\%) cases. HIV subtypes A (47.2\%) and D (34.4\%) were most common, $16.0 \%$ were recombinants. Subtypes C (1.8\%) and $\mathrm{G}(0.6 \%)$ were rarely seen. Relevant DRMs were observed in 135 (82.8\%), of which $103(63.2 \%)$ had resistance to 2 drug classes, and $11(6.7 \%)$ had resistance to all 3 drug classes available in Uganda. PI mutations were observed in $13(8.0 \%)$ patients. Any NRTI mutation was found in $122(74.8 \%)$ patients, most commonly M184V $(65.0 \%)$. A total of $125(76.7 \%)$ patients had any NNRTI mutation, most commonly K103N (42.9\%). Of the 163 patients with available resistance testing, $28(17.2 \%)$ had a K65R mutation. Almost all these patients were currently on treatment with tenofovir $(22 / 28,78.6 \%)$. Figure 3A, B show the resistance mutations found in patients failing first- and second-line ART with available sequence data.

In this study, resistance testing was performed only in patients with a viral load $>1000$ copies per milliliter. A viral load between 51 and 500 copies per milliliter was detected in $127(5.1 \%)$ participants (median viral load 130 copies per milliliter, IQR: 82-201 copies per milliliter), whereas 19
(0.8\%) study participants had a viral load between 501 and 999 copies per milliliter (median viral load 623 copies per milliliter, IQR: 565-797 copies per milliliter). Thus, if a cutoff of 50 copies per milliliter is applied, as is the case in resourcerich settings, the rate of virological failure almost doubles to 345 patients $(13.4 \%)$.

\section{DISCUSSION}

Our study indicates a low level of transmitted HIV drug resistance in this large urban HIV treatment center in a setting with public sector ART access for more than one and a half decades. Given the paucity of published HIV drug resistance studies in ART-naive individuals in the region, our findings provide some insight on the level of transmitted drug resistance for similar settings in the region. In addition, our study found a high rate of virological suppression. With over $92 \%$ of all patients virologically suppressed on ART, the overall prevalence of virological failure was low in our study population, and this is in line with the third of the $90-90-90^{17}$ UNAIDS targets. However, most failing patients had developed multiclass drug resistance.

\section{Transmitted Drug Resistance}

Although there are limited data available on acquired resistance in Uganda, there is even less on transmitted drug resistance among HIV-infected Ugandans. ${ }^{12}$ We found a proportion of $5.9 \%$ among our study population, which according to the WHO grading system is the cutoff between low $(<5 \%)$ and moderate $(5 \%-15 \%)$. Despite over 10 years of widespread ART availability in Uganda, according to this finding, the prevalence of transmitted drug resistance in adults seeking care in our clinic seems to be low. Furthermore, mutations to PI, which are commonly used as second-line treatment options, were not observed. These findings are in line with previous studies from Uganda, which showed low rates of transmitted drug resistance in rural areas, as well as in urban settings 10 years after the introduction of ART. ${ }^{6,18}$

The most recent report on HIV drug resistance published by the WHO found a high proportion of patients with pretreatment drug resistance in Uganda. ${ }^{15}$ According to the WHO definition, pretreatment drug resistance is detected in treatment-naive people initiating ART or people with previous antiretroviral drug exposure initiating or reinitiating first-line ART. Thus, pretreatment drug resistance includes transmitted drug resistance but can be acquired as well. The data on pretreatment drug resistance from Uganda included 342 adults (203 women, 65.4\%), of which 296 (78.7\%) had no previous exposure to ART. According to the report, levels of NNRTI pretreatment drug resistance were greater than $10 \%$ in 3 of 4 countries in the African region, ranging from 8.1\% (95\% CI: 4.3-14.7) in Cameroon to $15.4 \%$ (95\% CI: 10.3-22.5) in Uganda. Any transmitted DRM was found in $18.1 \%$ (95\% CI: $12.7-25.2)$ of Ugandan patients. Compared with the WHO report, our findings on transmitted drug resistance are much lower. Generally, surveillance data can be heterogeneous. The WHO report used a nationally representative sampling method described in detail in the report as 


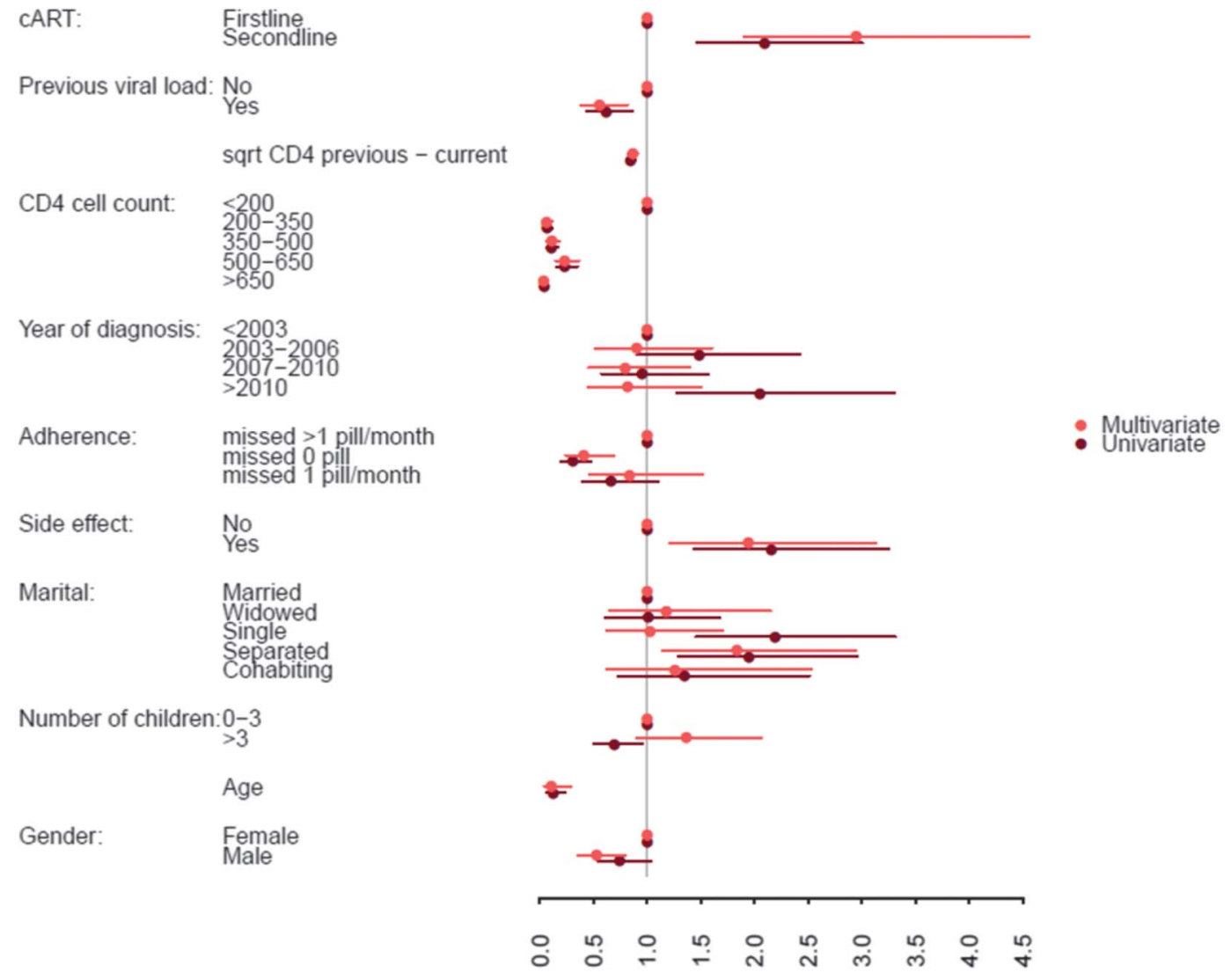

Odds ratio

FIGURE 2. Univariate and multivariate analysis of risk factors for virological failure. CART, combination antiretroviral therapy.

opposed to site-specific data. Second, considerable fluctuations over time have been observed in other countries, which can so far only partly be explained. One reason for these fluctuations was the introduction of new drugs as seen for boosted PIs in Switzerland. ${ }^{19}$ We conclude that more data are needed to complete the picture.

\section{Virological Failure}

Our study found a high rate of virological suppression. Using a cutoff for virological failure of 1000 copies per milliliter, over $92 \%$ of all patients were suppressed on ART, which is in line with the third of the 90-90-90 UNAIDS targets. ${ }^{17}$ This is especially encouraging because for several years, these patients were monitored using CD4 cell measurements only. Optimal adherence, high-quality clinical management, and consistent drug supplies probably contributed to these outcomes. The high proportion of patients virologically suppressed on first-line treatment is in line with findings from other studies previously conducted at the IDI. ${ }^{20}$ To maintain a high rate of virological suppression, the clinic adopted several differentiated care models, such as the nurse-visit or pharmacy-refill program. ${ }^{21}$ In both models, task shifting enables clinicians to concentrate on challenging cases. As the IDI is a center of excellence for HIV care, our study findings cannot be generalized. This aspect becomes even more apparent if our results are compared with the data provided by the UPHIA, which reports a prevalence of virological suppression among all HIV-positive Ugandan adults aged 15 to 64 years of only 59.6\% (62.9\% among females and $53.6 \%$ among males). ${ }^{5}$ However, the results of our study demonstrate how well patients can do within an optimal setting.

Nevertheless, it is notable that the proportion of patients with virological failure doubles if a cutoff of 50 copies per milliliter is applied, as is standard in many resource-rich settings. In our study, 146 patients had a viral load between 51 and 999 copies per milliliter. Using a cutoff of 1000 copies per milliliter for treatment failure makes sense in the context of "treatment as prevention," as it is well described that transmission practically does not take place below this cutoff. However, the development of HIV drug resistance among patients with low-level viremia may be underestimated. In fact, a recent nationwide study from France found that $48.5 \%$ of samples from patients with a viral load between 51 and 200 copies per milliliter harbored resistance mutations. ${ }^{22}$ Furthermore, recently published data from a South African cohort study that included over 70,000 HIV-positive patients from 57 clinical sites identified low-level viremia (defined as a viral 
TABLE 2. Univariate and Multivariate Analyses of Risk Factors for Virological Failure in A) Patients on First-Line ART and B) Patients On Second-Line ART

\begin{tabular}{|c|c|c|c|c|c|c|}
\hline \multirow[b]{2}{*}{ Variable } & \multicolumn{3}{|c|}{ Univariate Analysis } & \multicolumn{3}{|c|}{ Multivariate Analysis } \\
\hline & OR & $95 \% \mathrm{CI}$ & $P$ & OR & $95 \% \mathrm{CI}$ & $P$ \\
\hline \multicolumn{7}{|l|}{$\begin{array}{l}\text { A) Patients on First- } \\
\text { Line ART }\end{array}$} \\
\hline Age & 0.12 & $\begin{array}{c}0.06 .0 \text { to } \\
24\end{array}$ & $<0.001$ & 0.07 & $\begin{array}{r}0.02 \text { to } \\
0.22\end{array}$ & $<0.001$ \\
\hline Male sex & 0.74 & $\begin{array}{r}0.54 \text { to } \\
1.03\end{array}$ & 0.08 & 0.44 & $\begin{array}{r}0.27 \text { to } \\
0.71\end{array}$ & $<0.001$ \\
\hline \multicolumn{7}{|l|}{$\begin{array}{l}\text { CD } 4 \text { cell count in } \\
\text { cells } / \mu 1\end{array}$} \\
\hline \multicolumn{7}{|l|}{$<200$ (reference) } \\
\hline $200-350$ & 0.07 & $\begin{array}{r}0.04 \text { to } \\
0.12\end{array}$ & $<0.001$ & 0.04 & $\begin{array}{r}0.02 \text { to } \\
0.09\end{array}$ & $<0.001$ \\
\hline $351-500$ & 0.12 & $\begin{array}{r}0.07 \text { to } \\
0.17\end{array}$ & $<0.001$ & 0.08 & $\begin{array}{r}0.04 \text { to } \\
0.14\end{array}$ & $<0.001$ \\
\hline $501-650$ & 0.23 & $\begin{array}{r}0.15 \text { to } \\
0.35\end{array}$ & $<0.001$ & 0.19 & $\begin{array}{r}0.11 \text { to } \\
0.32\end{array}$ & $<0.001$ \\
\hline$>650$ & 0.04 & $\begin{array}{r}0.02 \text { to } \\
0.08\end{array}$ & $<0.001$ & 0.02 & $\begin{array}{r}0.01 \text { to } \\
0.06\end{array}$ & $<0.001$ \\
\hline Previous viral load & 0.62 & $\begin{array}{r}0.44 \text { to } \\
0.86\end{array}$ & 0.005 & 0.64 & $\begin{array}{r}0.41 \text { to } \\
0.99\end{array}$ & 0.05 \\
\hline \multicolumn{7}{|l|}{$\begin{array}{l}>1 / \text { mo } \\
\text { (reference) }\end{array}$} \\
\hline Never & 0.31 & $\begin{array}{r}0.2 \text { to } \\
0.48\end{array}$ & $<0.001$ & 0.33 & $\begin{array}{r}0.18 \text { to } \\
0.61\end{array}$ & $<0.001$ \\
\hline $1 / \mathrm{mo}$ & 0.66 & $\begin{array}{c}0.39 \text { to } \\
1.1\end{array}$ & 0.11 & 0.79 & $\begin{array}{r}0.4 \text { to } \\
1.55\end{array}$ & 0.49 \\
\hline Side effects & 2.16 & $\begin{array}{r}1.43 \text { to } \\
3.25\end{array}$ & $<0.001$ & 2.01 & $\begin{array}{r}1.17 \text { to } \\
3.46\end{array}$ & 0.01 \\
\hline \multicolumn{7}{|l|}{ Marital status } \\
\hline \multicolumn{7}{|l|}{$\begin{array}{l}\text { Married } \\
\text { (reference) }\end{array}$} \\
\hline Single & 2.19 & $\begin{array}{r}1.45 \text { to } \\
3.31\end{array}$ & $<0.001$ & 0.98 & $\begin{array}{r}0.54 \text { to } \\
1.78\end{array}$ & 0.95 \\
\hline Separated & 1.95 & $\begin{array}{r}1.29 \text { to } \\
2.96\end{array}$ & 0.002 & 2.21 & $\begin{array}{r}1.29 \text { to } \\
3.81\end{array}$ & 0.004 \\
\hline Widowed & 1.01 & $\begin{array}{r}0.61 \text { to } \\
1.68\end{array}$ & 0.98 & 1.36 & $\begin{array}{r}0.68 \text { to } \\
2.76\end{array}$ & 0.39 \\
\hline Cohabitating & 1.35 & $\begin{array}{c}0.72 \text { to } \\
2.51\end{array}$ & 0.35 & 1.43 & $\begin{array}{r}0.65 \text { to } \\
3.14\end{array}$ & 0.38 \\
\hline \multicolumn{7}{|l|}{ No. of children } \\
\hline$>3$ & 0.70 & $\begin{array}{r}0.5 \text { to } \\
0.96\end{array}$ & 0.03 & 1.45 & $\begin{array}{r}0.89 \text { to } \\
2.35\end{array}$ & 0.14 \\
\hline
\end{tabular}

load of 51-999 copies per milliliter) in $23 \%$ of patients on first-line treatment. According to the authors, low-level viremia was associated with increased hazards of virological failure (hazard ratio $2 \cdot 6,95 \% \mathrm{CI}: 2 \cdot 5-2 \cdot 8 ; P<0 \cdot 0001$ ) and switch to second-line ART (hazard ratio $5 \cdot 2,4 \cdot 4-6 \cdot 1 ; P<$ $0 \cdot 0001])$ compared with virological suppression of less than 50 copies per milliliter. ${ }^{23}$ These findings challenge the definition of therapeutic failure in guidelines using a cutoff of 1000 copies per milliliter, and evidence suggests that strategies for the management of low-level viremia need to be
TABLE 2. (Continued) Univariate and Multivariate Analyses of Risk Factors for Virological Failure in A) Patients on First-Line ART and B) Patients On Second-Line ART

\begin{tabular}{|c|c|c|c|c|c|c|}
\hline \multirow[b]{2}{*}{ Variable } & \multicolumn{3}{|c|}{ Univariate Analysis } & \multicolumn{3}{|c|}{ Multivariate Analysis } \\
\hline & $\mathbf{O R}$ & $95 \% \mathrm{CI}$ & $P$ & $\mathbf{O R}$ & $95 \% \mathrm{CI}$ & $P$ \\
\hline \multicolumn{7}{|l|}{$\begin{array}{l}\text { B) Patients on Second- } \\
\text { Line ART }\end{array}$} \\
\hline Age & 0.12 & $\begin{array}{r}0.06 \text { to } \\
2.97\end{array}$ & 0.39 & 0.43 & $\begin{array}{r}0.06 \text { to } \\
2.97\end{array}$ & 0.39 \\
\hline Male sex & 0.74 & $\begin{array}{r}0.54 \text { to } \\
1.03\end{array}$ & 0.08 & 0.81 & $\begin{array}{r}0.35 \text { to } \\
1.87\end{array}$ & 0.62 \\
\hline \multicolumn{7}{|l|}{$\begin{array}{l}\mathrm{CD} 4 \text { cell count in } \\
\text { cells } / \mu \mathrm{l}\end{array}$} \\
\hline$<200$ (reference) & & $\begin{array}{r}(0.04 \text { to } \\
0.12)\end{array}$ & & & & \\
\hline $200-350$ & 0.07 & $\begin{array}{r}(0.07 \text { to } \\
0.17)\end{array}$ & $<0.001$ & 0.27 & $\begin{array}{r}(0.07 \text { to } \\
1.03)\end{array}$ & 0.06 \\
\hline $351-500$ & 0.11 & $\begin{array}{r}(0.15 \text { to } \\
0.35)\end{array}$ & $<0.001$ & 0.60 & $\begin{array}{r}(0.19 \text { to } \\
1.86)\end{array}$ & 0.37 \\
\hline $501-650$ & 0.23 & $\begin{array}{r}(0.02 \text { to } \\
0.08)\end{array}$ & $<0.001$ & 0.70 & $\begin{array}{r}(0.23 \text { to } \\
2.13)\end{array}$ & 0.53 \\
\hline$>650$ & 0.04 & & $<0.001$ & 0.10 & $\begin{array}{r}(0.03 \text { to } \\
0.41)\end{array}$ & 0.001 \\
\hline Previous viral load & 0.62 & $\begin{array}{r}(0.44 \text { to } \\
0.86)\end{array}$ & 0.01 & 0.21 & $\begin{array}{r}(0.09 \text { to } \\
0.52)\end{array}$ & $<0.001$ \\
\hline \multicolumn{7}{|l|}{ Missed pills } \\
\hline \multicolumn{7}{|l|}{$\begin{array}{l}>1 / \text { mo } \\
\text { (reference) }\end{array}$} \\
\hline Never & 0.31 & $\begin{array}{l}(0.2 \text { to } \\
0.48)\end{array}$ & $<0.001$ & 1.11 & $\begin{array}{r}(0.34 \text { to } \\
3.58)\end{array}$ & 0.87 \\
\hline $1 / \mathrm{mo}$ & 0.66 & $\begin{array}{c}(0.39 \text { to } \\
1.1)\end{array}$ & 0.11 & 1.28 & $\begin{array}{r}(0.31 \text { to } \\
5.23)\end{array}$ & 0.73 \\
\hline Side effects & 2.18 & $\begin{array}{r}(1.43 \text { to } \\
3.25)\end{array}$ & $<0.001$ & 1.34 & $\begin{array}{c}(0.39 \text { to } \\
4.55)\end{array}$ & 0.64 \\
\hline \multicolumn{7}{|l|}{ Marital status } \\
\hline \multicolumn{7}{|l|}{$\begin{array}{l}\text { Married } \\
\text { (reference) }\end{array}$} \\
\hline Single & 2.19 & $\begin{array}{r}(1.45 \text { to } \\
3.31)\end{array}$ & $<0.001$ & 1.46 & $\begin{array}{r}(0.55 \text { to } \\
3.92)\end{array}$ & 0.45 \\
\hline Separated & 1.95 & $\begin{array}{r}(1.29 \text { to } \\
2.96)\end{array}$ & 0.001 & 0.81 & $\begin{array}{r}(0.27 \text { to } \\
2.47)\end{array}$ & 0.71 \\
\hline Widowed & 1.01 & $\begin{array}{r}(0.61 \text { to } \\
1.68)\end{array}$ & 0.98 & 0.64 & $\begin{array}{r}(0.19 \text { to } \\
2.17)\end{array}$ & 0.47 \\
\hline Cohabitating & 1.35 & $\begin{array}{r}(0.72 \text { to } \\
2.51)\end{array}$ & 0.35 & 0.80 & $\begin{array}{r}(0.15 \text { to } \\
4.14)\end{array}$ & 0.80 \\
\hline \multicolumn{6}{|l|}{ No. of children } & \\
\hline$>3$ & 0.70 & $\begin{array}{l}(0.5 \text { to } \\
0.96)\end{array}$ & 0.03 & 1.36 & $\begin{array}{r}(0.59 \text { to } \\
3.11)\end{array}$ & 0.47 \\
\hline
\end{tabular}

incorporated into international guidelines to meet UNAIDSdefined targets.

\section{Acquired Drug Resistance}

The high proportion of virological suppression on ART is encouraging. However, most study participants with virological failure had developed resistance to more than 1 drug class, suggesting that failing regimens not identified by CD4 cell count monitoring in a timely fashion had been in place for a prolonged period. This study finding is most worrisome, as efficacious treatment options are limited for 
FIGURE 3. A, Type and frequency of most prevalent resistance-associated mutations observed among patients failing first-line antiretroviral treatment $(\mathrm{N}=121)$. B, Type and frequency of most prevalent resistance-associated mutations observed among patients failing second-line antiretroviral treatment $(N=36)$.
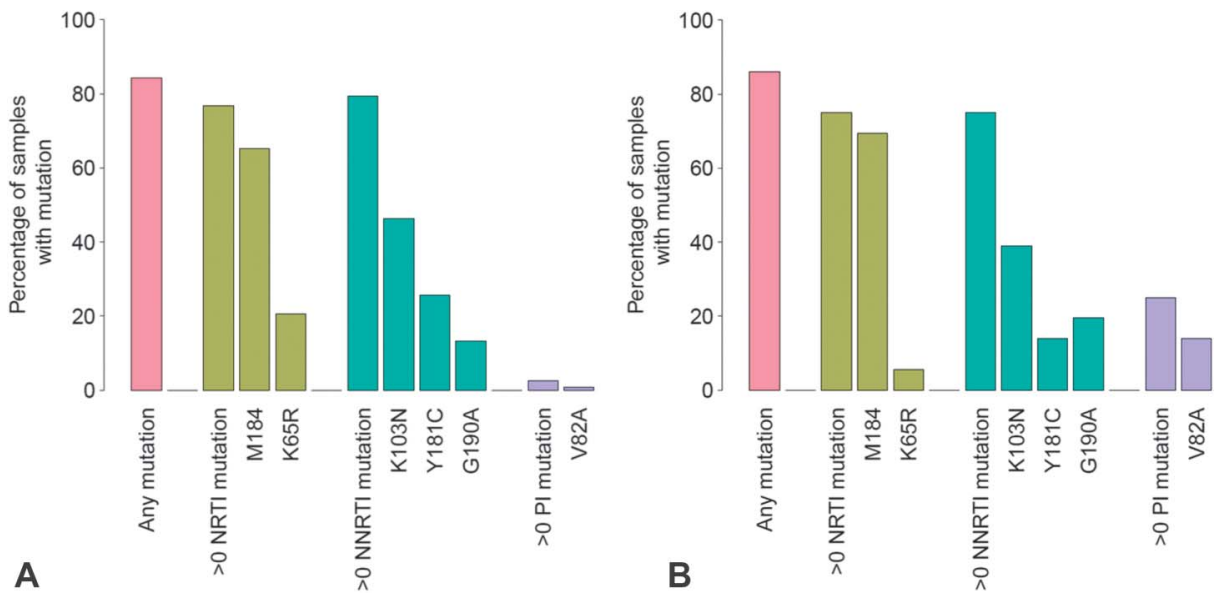

patients with multiclass drug resistance in this setting, which puts these patients at high risk of disease progression and transmission of resistant virus strains. The accumulation of DRMs over time in patients with continued virological failure was shown in previously conducted studies from Uganda and other sub-Saharan African countries. ${ }^{24,25}$ A systematic review and meta-analysis that included 8376 patients from 8 cohorts and 2 prospective studies showed a significantly higher proportion of resistance mutations at virological failure in patients monitored less frequently. ${ }^{26}$ This is in line with our observation that previous viral load measurements were protective of virological failure and thus the development of resistance mutations in patients on second-line ART.

The distribution of mutations found in our study is largely in line with findings from other studies conducted in the region. A systematic review of 89 studies with 13,288 patients from sub-Saharan Africa found the prevalence of viral suppression at 12 months to be $76 \%{ }^{27}$ In patients with virological failure, the most common resistance mutations reported by the authors were M184V (65\%) and K103N $(52 \%)$, whereas thymidine analog mutations (TAMs) and K65R were much less common (5\%-20\%). The PharmAccess African Studies to Evaluate Resistance (PASER), which evaluated data from 6 African countries, found that $8.5 \%$ of patients with virological failure after 11-15 months of ART have more than 1 TAM. $^{28}$

Among the 163 patients with available resistance data in our study, $54(33.1 \%)$ were on TDF-containing regimens. Of these, $22(40.7 \%)$ had a K65R mutation compared with only $28(17.8 \%)$ among the entire study population. A recent study on the global epidemiology of HIV drug resistance after failure of WHO recommended first-line regimens was recently published. ${ }^{29}$ In low- and middle-income countries, the authors found drug resistance in a high proportion of patients failing treatment with tenofovir-containing regimens. Tenofovir resistance was highest in sub-Saharan Africa (370/ $654,57 \%)$. The study findings reported here, as well as observations from other studies on emergence of resistance in the region stress the need for enhanced surveillance and preventive measures. ${ }^{30,31}$

Our study has a few limitations. For one, women currently without ART but with a history of PMTCT (WHO option B) were excluded from participation. These women were excluded because they did not fulfill the criteria of being ART naive or on a stable regimen for at least 6 months. However, HIV drug resistance today plays an important role in these women, and further research focused specifically on this group is needed. A further limitation is that we failed to collect information on pregnancy, as well as on tuberculosis coinfection. Both aspects are relevant in the context of treatment failure and should have been taken into account. Furthermore, a number of resistance tests failed. We were unable to ascertain the cause of failure to genotype 54 samples of ART-naive and 36 samples of ART-experienced participants. Although this did not result in a selection bias, it reduced the number of available tests for this study analysis. However, the number of failed test seems to be in line with other studies. $^{22}$

We conclude that the UNAIDS goal of $90 \%$ virological suppression on ART is achievable within an optimal treatment setting. However, if treatment failure occurred, a high proportion had developed multiclass drug resistance, which massively complicates sufficient treatment in this setting. Furthermore, if a cutoff for treatment failure of 50 copies per milliliter is applied, the rate of patients with virological failure doubles and most likely resistance among these patients is underestimated. As ART scale-up continues in the region, close surveillance of HIV drug resistance - both acquired and transmitted - is essential to assess optimal treatment regimens available to patients, and thereby prevent the further emergence and spread of resistant strains.

\section{ACKNOWLEDGMENTS}

The authors acknowledge all patients and their families. The authors especially thank Ms. Veronicah Kizza for her dedicated patient care and excellent work as our study nurse.

\section{REFERENCES}

1. Kabugo C, Bahendeka S, Mwebaze R, et al. Long-term experience providing antiretroviral drugs in a fee-for-service HIV clinic in Uganda: evidence of extended virologic and CD4+ cell count responses. J Acquir Immune Defic Syndr. 2005;38:578-583. 
2. Zuniga J. Out of Africa: Uganda and UNAIDS advance a bold experiment. J Int Assoc Physicians AIDS Care. 1999;5:48-60.

3. Gillespie S. AIDS, Poverty, and Hunger: International Food Policy Research Institute (IFPRI); 2006. Available at: https://core.ac.uk/ download/pdf/6289136.pdf.

4. WHO. Consolidated Guidelines on the use of Antiretroviral Drugs for Treating and Preventing HIV Infection. Recommendations for a Public Health Approach. 2 ed; 2016.

5. Uganda Population-Based HIV Impact Assessment (UPHIA 2016-2017) Available at: http://www.afro.who.int/sites/default/files/2017-08/UPHIA \%20Uganda\%20factsheet.pdf. Accessed December 12, 2017.

6. Lee GQ, Bangsberg DR, Muzoora C, et al. Prevalence and virologic consequences of transmitted HIV-1 drug resistance in Uganda. AIDS Res Hum Retroviruses. 2014;30:896-906.

7. Nazziwa J, Njai HF, Ndembi N, et al. Short communication: HIV type 1 transmitted drug resistance and evidence of transmission clusters among recently infected antiretroviral-naive individuals from Ugandan fishing communities of Lake Victoria. AIDS Res Hum Retroviruses. 2013;29:788-795.

8. Günthard HF, Saag MS, Benson CA, et al. Antiretroviral drugs for treatment and prevention of HIV infection in adults: 2016 recommendations of the international antiviral Society-USA panel. JAMA. 2016;316:191-210.

9. Gupta RK, Jordan MR, Sultan BJ, et al. Global trends in antiretroviral resistance in treatment-naive individuals with HIV after rollout of antiretroviral treatment in resource-limited settings: a global collaborative study and meta-regression analysis. Lancet. 2012;380:1250-1258.

10. Hamers RL, Sigaloff KCE, Kityo C, et al. Wit TFR de. Emerging HIV-1 drug resistance after roll-out of antiretroviral therapy in sub-Saharan Africa. Curr Opin HIV AIDS. 2013;8:19-26.

11. Ssemwanga D, Lihana RW, Ugoji $C$, et al. Update on HIV-1 acquired and transmitted drug resistance in Africa. AIDS Rev. 2015;17:3-20.

12. Kaleebu P, Kirungi W, Watera C, et al. Virological response and antiretroviral drug resistance emerging during antiretroviral therapy at three treatment centers in Uganda. PLoS One. 2015;10:e145536.

13. Nwaka S, Ochem A, Besson D, et al. Analysis of pan-African Centres of excellence in health innovation highlights opportunities and challenges for local innovation and financing in the continent. BMC Int Health Hum Rights. 2012;12:11.

14. Castelnuovo B, Nsumba M, Musomba R, et al. Strengthening the "viral failure pathway": clinical decision and outcomes of patients with confirmed viral failure in a large HIV care clinic in Uganda. $J$ Acquir Immune Defic Syndr. 2015;70:e174-6.

15. WHO. HIV drug resistance report 2017: IGO; 2017. Licence: CC BYNC-SA 3.0. Available at: http://apps.who.int/iris/bitstream/handle/10665/ 255896/9789241512831-eng.pdf?sequence $=1$.

16. Castelnuovo B, Kiragga A, Afayo V, et al. Implementation of provider-based electronic medical records and improvement of the quality of data in a large HIV program in Sub-Saharan Africa. PLoS One. 2012;7:e51631.

17. UNAIDS. 90-90-90: An Ambitious Treatment Target to Help End the Aids Epidemic; 2014. Available at: http://www.unaids.org/sites/default/ files/media_asset/90-90-90_en.pdf.
18. Reynolds SJ, Ssempijja V, Galiwango R, et al. Low rates of transmitted drug resistance among newly identified HIV-1 seroconverters in rural Rakai, Uganda. AIDS Res Hum Retroviruses. 2017;33:448-451.

19. Yang W-L, Kouyos R, Scherrer AU, et al. Assessing the paradox between transmitted and acquired HIV type 1 drug resistance mutations in the Swiss HIV cohort study from 1998 to 2012. J Infect Dis. 2015;212:28-38.

20. Castelnuovo B, Kiragga A, Mubiru F, et al. First-line antiretroviral therapy durability in a 10-year cohort of naïve adults started on treatment in Uganda. J Int AIDS Soc. 2016;19:20773.

21. Nakiwogga-Muwanga A, Katabira E, Kiragga A, et al. Factors before enrolment are associated with being removed from a Pharmacy-only Refill Programme at a large urban HIV/AIDS clinic, Uganda. Int J STD AIDS. 2014;25:105-112.

22. Assoumou L, Charpentier C, Recordon-Pinson P, et al. Prevalence of HIV-1 drug resistance in treated patients with viral load 50 copies $/ \mathrm{mL}$ : a 2014 French nationwide study. J Antimicrob Chemother. 2017;72: $1769-1773$.

23. Hermans LE, Moorhouse M, Carmona S, et al. Effect of HIV-1 low-level viraemia during antiretroviral therapy on treatment outcomes in WHOguided South African treatment programmes: a multicentre cohort study. Lancet Infect Dis. 2018;18:188-197.

24. Reynolds SJ, Sendagire H, Newell K, et al. Virologic versus immunologic monitoring and the rate of accumulated genotypic resistance to firstline antiretroviral drugs in Uganda. BMC Infect Dis. 2012;12:381

25. Boender TS, Kityo CM, Boerma RS, et al. Accumulation of HIV-1 drug resistance after continued virological failure on first-line ART in adults and children in sub-Saharan Africa. J Antimicrob Chemother. 2016;71: $2918-2927$.

26. Gupta RK, Hill A, Sawyer AW, et al. Virological monitoring and resistance to first-line highly active antiretroviral therapy in adults infected with HIV-1 treated under WHO guidelines: a systematic review and meta-analysis. Lancet Infect Dis. 2009;9:409-417.

27. Barth RE, van der Loeff MFS, Schuurman R, et al. Virological follow-up of adult patients in antiretroviral treatment programmes in sub-Saharan Africa: a systematic review. Lancet Infect Dis. 2010;10:155-166.

28. Hamers RL, Oyomopito R, Kityo C, et al. Cohort profile: the PharmAccess African (PASER-M) and the TREAT Asia (TASER-M) monitoring studies to evaluate resistance-HIV drug resistance in subSaharan Africa and the Asia-Pacific. Int J Epidemiol. 2012;41:43-54.

29. Global epidemiology of drug resistance after failure of WHO recommended first-line regimens for adult HIV-1 infection: a multicentre retrospective cohort study. Lancet Infect Dis. 2016;16:565-575.

30. Hassan AS, Nabwera HM, Mwaringa SM, et al. HIV-1 virologic failure and acquired drug resistance among first-line antiretroviral experienced adults at a rural HIV clinic in coastal Kenya: a cross-sectional study. AIDS Res Ther. 2014;11:9.

31. Lessells RJ, Stott KE, Manasa J, et al. Implementing antiretroviral resistance testing in a primary health care HIV treatment programme in rural KwaZulu-Natal, South Africa: early experiences, achievements and challenges. BMC Health Serv Res. 2014;14:116. 